\title{
Test and Evaluation of Stiffness of a Pin Turning Device for Large Marine Engine Crankshafts
}

\author{
Y. H. Choi ${ }^{1}$, G. B. Ha ${ }^{2}$, D. H. Kim ${ }^{2}$, H. S. $\mathrm{An}^{3}$ \\ ${ }^{1}$ Department of Mechanical Engineering, Changwon National University, Changwon, Korea; ${ }^{2}$ Department of Mechanical Design \\ Engineering, Graduate School of Changwon National University, Changwon, Korea; ${ }^{3}$ Research Institute, HNK Machine Tool Co., \\ Ltd., Haman, Korea. \\ Email: yhchoi@changwon.ac.kr
}

Received October 2013

\begin{abstract}
In order to prevent unwanted excited vibrations and to secure better machining precision in large size heavy duty machine tools dynamic stiffness is one of the most desirable and critical properties. In the past decades, many researches on machine tool stiffness test and evaluation methodology have been made. However any methodology for a Pin Turning Device (PTD), which is a special kind of turning lathe for machining big size crankshaft pins, is rarely found among them. This study proposes a test and evaluation process of stiffness of a PTD by measuring frequency response function at the tool center point (TCP). For conformance proving for the proposed methodology, stiffness of a PTD obtained by the proposed method with impact hammer test (IHT) has been compared with that determined by FEM.
\end{abstract}

Keywords: Pin Turning Device (PTD); Machine Tool Stiffness; Compliance Response Function; Impact Hammer Test

\section{Introduction}

Recently there is an increasing demand for large scale machine tools for large and precision parts for several high growth industry fields like; conventional and renewable energy power plants, airplane structures, offshore platforms, ships and marine engines, etc. [1,9,10]. For large size machine tool, reduced structural stiffness compared to smaller machine tool is one of problems to be resolved because deflection of a machine structure rises as an exponential function of its dimension while the allowable deflection increases linearly [9]. In the past decades, many researchers have studied machine tool stiffness evaluation methodologies and design optimization for high structural rigidity and lightweight [2-8]. Machine tool stiffness evaluation method [3,4] by determining the compliance frequency response function at TCP is a more economical and analytical way than that by a direct cutting test. Thus, this method has been broadly applied to obtaining machine tool stiffness. Typical stiffness evaluation methodologies for many different types of machine tools have been studied by M. Weck and K. Teipel [4] except that for a special purpose lathe like a PTD for machining crankshaft pins as shown Figure 1. The PTD has volumetric dimension of $4 \times 1 \times 4.5\left(\mathrm{~m}^{3}\right)$.

For turning operation of the PTD, a revolving ring built in tool post rotates around a fixed workpiece differed from a general lathe, in which a workpiece is rotat- ing and tool is moved (indexed) by a tool post. The tool post of the PTD can be indexed in the radial direction only. Thus cutting forces correspondingly occur in the radial and tangential directions. Moreover there is a strong possibility that the PTD does not show uniform stiffness in the radial and tangential directions along the circumference because the PTD has an asymmetric structure and open and close type revolving ring as illustrated in Figure 1. Therefore stiffness in the radial and tangential directions is a critical influential parameter upon dynamic behavior and machining accuracy of the PTD. Thus this study proposes a proper test and evaluation methodology of stiffness of a PTD.

\section{Test and Evaluation of a PTD Stiffness}

\subsection{Test Methodology and Process}

According to M. Weck and K. Teipel [4], stiffness of a machine tool can be determined from reciprocal of the compliance measured at TCP as shown in Figure 2. From the view point of theoretical basis, the PTD stiffness evaluation methodology in this study is almost the same as theirs [4]. However there is not specified any method or process for a PTD in [4], so we propose a test and evaluation methodology of a PTD stiffness as illustrated in Figure 3. The static stiffness $k_{s}$ and dynamic stiffness $k_{d}$ are defined by Equation (1) and Equation 


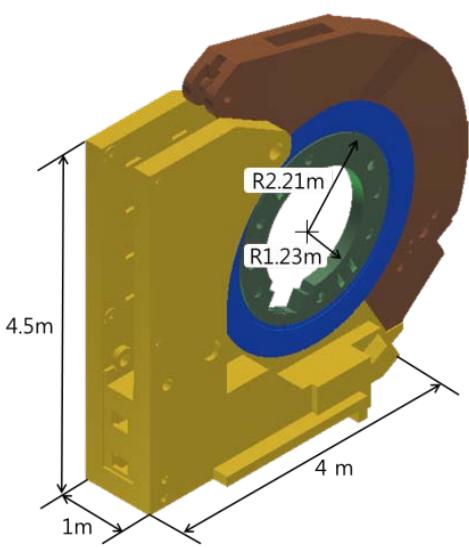

(a) Open \& close type PTD

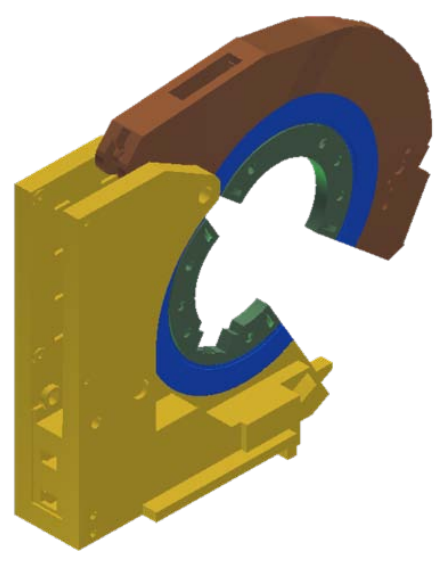

Figure 1. Solid model and prototype of a PTD.

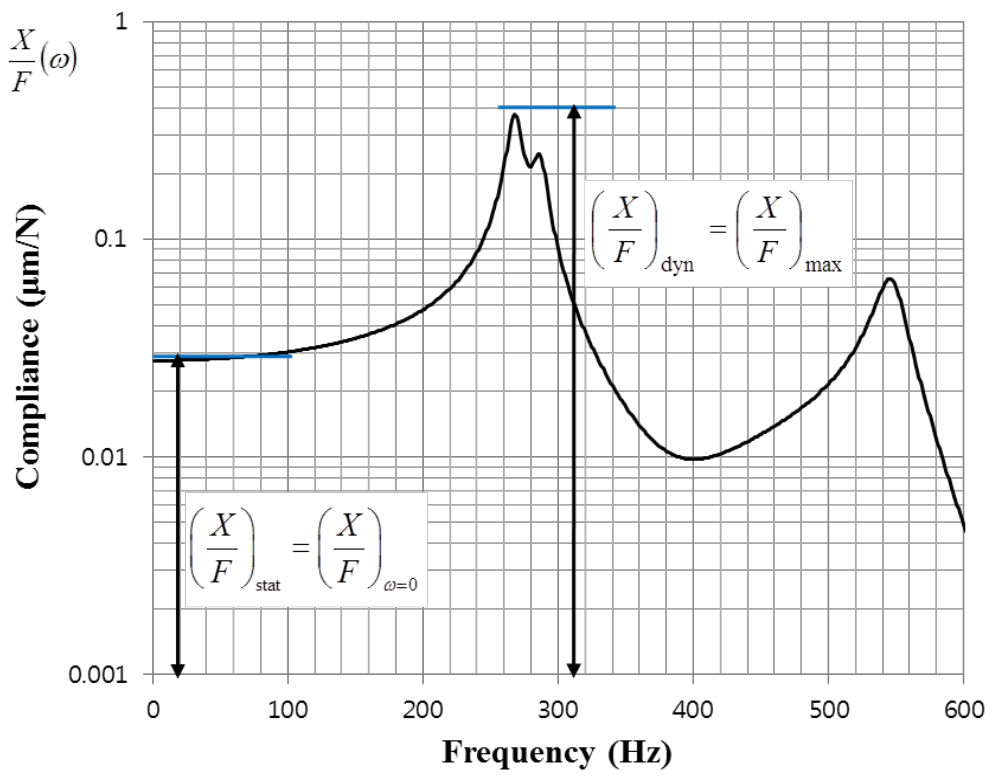

Figure 2. A typical sample of measured compliance at TCP.

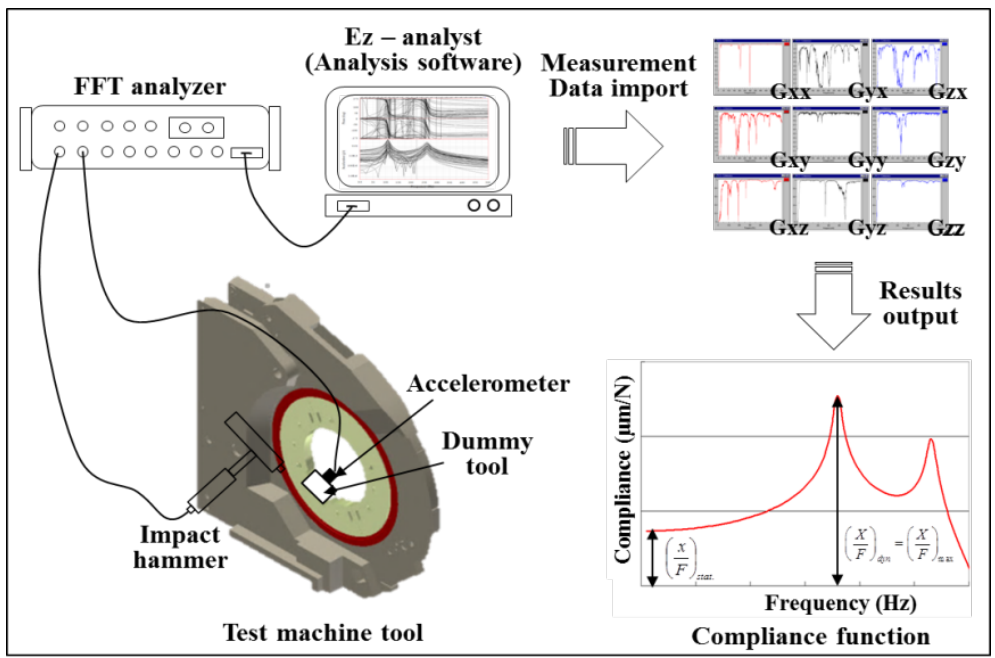

Figure 3. An explanatory flow of the proposed PTD stiffness test methodology. 
(2), respectively. For a PTD, static and stiffness deviations $\Delta k_{s}$ and $\Delta k_{d}$ defined by Equations (3) and (4), of course, will be reasonable and useful criteria considering that the PTD has asymmetric structure and its tool post with the revolving ring turns around a work piece in the vertical plane.

$$
\begin{gathered}
k_{s}=1 /\left(\frac{X}{F}\right)_{\omega \approx 0} \\
k_{d}=1 /\left(\frac{X}{F}\right)_{\text {max }} \\
\left.\left.\Delta k_{s}=k_{s}\right)_{\text {max }}-k_{s}\right)_{\text {min }} \\
\left.\left.\Delta k_{d}=k_{d}\right)_{\text {max }}-k_{d}\right)_{\text {min }}
\end{gathered}
$$

Where $F$ and $X$ are excitation force and displacement at TCP of the machine tool, respectively.

The coordinate systems and parameters for measurement position are defined as shown in Figure 4(a). Cartesian coordinate system is used for defining global coordinates of the PTD structure and a local polar coordinate system is used for defining coordinates of the circular parts and revolving motions. The parameters $M, R_{R}$, $R_{M}$ represent the measurement position, the radius of revolving ring, the radial distance of the measurement position (the distance between the position $M$ and the revolving ring center), respectively. A dummy tool shown in Figure 4(b) is installed into the tool post of the PTD and a tri-axial accelerometer is attached on it. The radial distance of measurement point $R_{M}$ is apparently decided as following equation.

$$
R_{M}=R_{R}-\left(r_{T P} / 2+h_{D T}\right)
$$

Where $r_{T P}$ and $h_{D T}$ are the feed of tool post in the radial axis and the dummy tool height, respectively.

Compliance due to applied impulse force or random excitation has been measured at 12 evenly indexed TCPs as shown in Figures 4(c) and (d). Consequently stiffness has been obtained from the measured compliance. For measuring compliance of the PTD, some measuring devices were used as; FFT analyzer (ZonicBook 618E), impact hammer (PCB Model 086D50), tri-axial accelerometer (Kistler Type 8795A50).

\subsection{FEM Analysis of PTD Stiffness}

In order to predict the compliance of the PTD analytically and to compare with test results, in this study, harmonic response analysis also has been carried out. FEM model of the PTD for the harmonic response analysis is shown in Figure 5. The modeling data and applied force are given in Table 1. Compliance frequency responses were analyzed in each case of harmonic excitation applied to the evenly indexed 12 different TCPs as shown in Figure 4(c). As the result, the static and dynamic compliances at each of the 12 different TCPs were obtained and consequently the corresponding static and dynamic stiffness and their deviations were computed by using Equations (1)-(4).

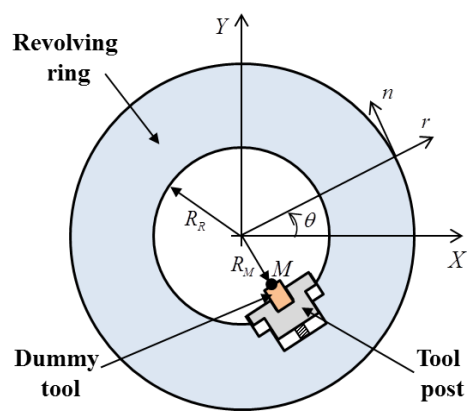

(a) Coordinate system

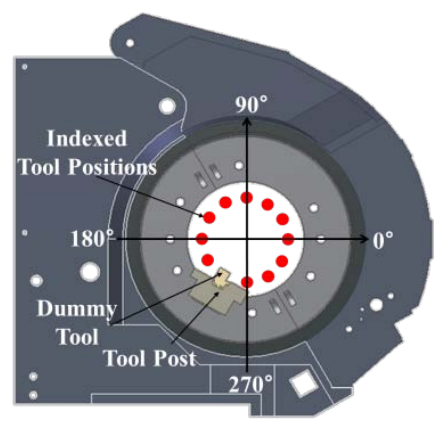

(c) Measuring positions

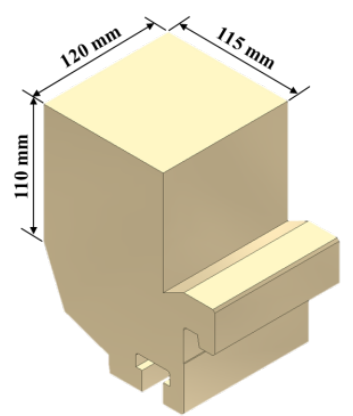

(b) A dummy tool design

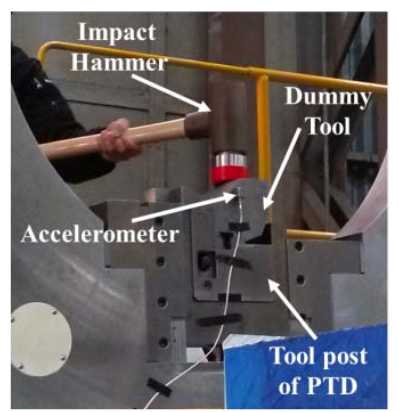

(d) Impact hammer \& pickup

Figure 4. Coordinate system, measuring positions, and equipment for the PTD stiffness test methodology. 
Table 1. Modeling data for FEM analysis of the PTD.

\begin{tabular}{|c|c|c|c|c|}
\hline \multirow{2}{*}{ FEM modeling } & Element type & \multicolumn{2}{|l|}{ No. of nodes } & No. of elements \\
\hline & SHEL 63 & 10,439 & & 11,031 \\
\hline \multirow{3}{*}{ Material property } & Material & Elasticity $(\mathbf{G P a})$ & Poisson's ratio & Density \\
\hline & GCD 500 & 172 & 0.275 & 7200 \\
\hline & SCM 440 & 205 & 0.29 & 7850 \\
\hline \multirow{2}{*}{ Applied force at spindles } & Direction & Radial dir. & \multicolumn{2}{|r|}{ Tangential dir. } \\
\hline & Force $(N)$ & 3623 & \multicolumn{2}{|r|}{13,523} \\
\hline Boundary conditions & \multicolumn{4}{|c|}{4 supporting nodes at the bottom are fixed } \\
\hline
\end{tabular}

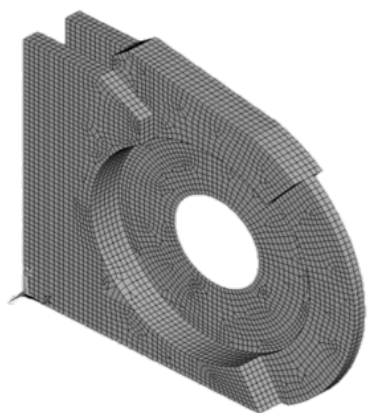

Figure 5. FEM model of the PTD.

\section{Results and Discussion}

For verifying conformance of the proposed methodology, both measured and computed stiffness at 12 evenly indexed TCPs have been compared with each other and they look alike as observed in Figures $\mathbf{6}$ and 7 and Tables 2 and 3.

As seen in Table 2, measured static stiffness (minimum stiffness value) of the PTD was $1.666 \mathrm{kN} / \mu \mathrm{m}$ in the radial direction and $5.000 \mathrm{kN} / \mu \mathrm{m}$ in the tangential direction, respectively. Computed static stiffness was $1.370 \mathrm{kN} /$ $\mu \mathrm{m}$ in the radial direction and $3.367 \mathrm{kN} / \mu \mathrm{m}$ in the tangential direction, respectively.

Similarly as seen in Table 3, measured dynamic stiffness of the PTD was $54.1 \mathrm{~N} / \mu \mathrm{m}$ in the radial direction and $111.1 \mathrm{~N} / \mu \mathrm{m}$ in the tangential direction, respectively. And the computed dynamic stiffness was $39.1 \mathrm{~N} / \mu \mathrm{m}$ in the radial direction and $100 \mathrm{~N} / \mu \mathrm{m}$ in the tangential direction, respectively

Judged by the test results, static stiffness deviation was $3.334 \mathrm{kN} / \mu \mathrm{m}$ in the radial direction and $28.333 \mathrm{kN} / \mu \mathrm{m}$ in the tangential direction, respectively. And also dynamic stiffness deviation was $173.2 \mathrm{~N} / \mu \mathrm{m}$ in the radial direction and 297.1 N/ $\mu \mathrm{m}$ in the tangential direction, respectively. So, the proposed PTD stiffness test methodology has been proven to be valid for determining real stiffness of a PTD.

\section{Concluding Remarks}

In this study, a test and evaluation methodology of stiffness of a PTD, which is special purpose turning lathe for

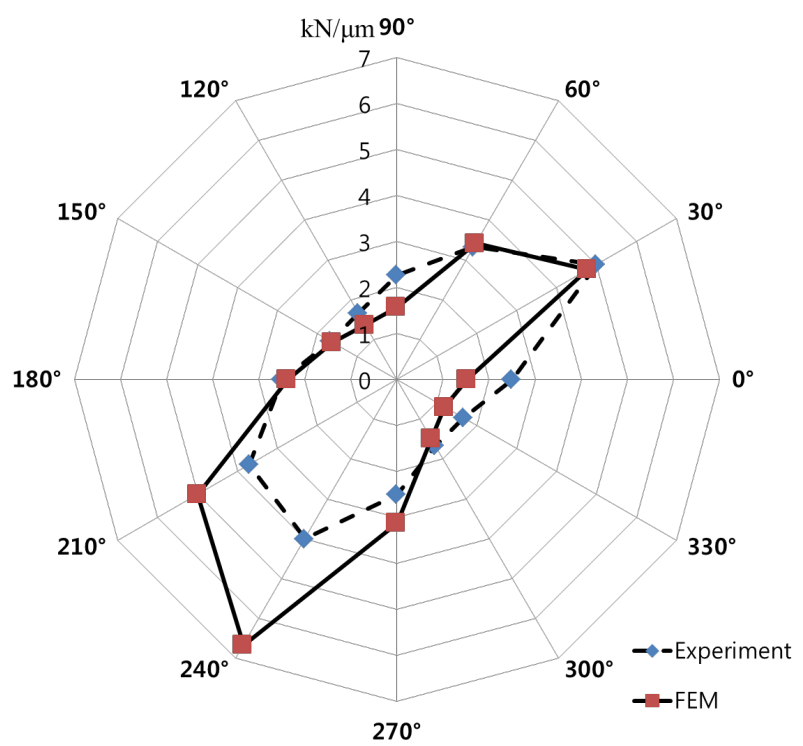

(a) In the radial direction

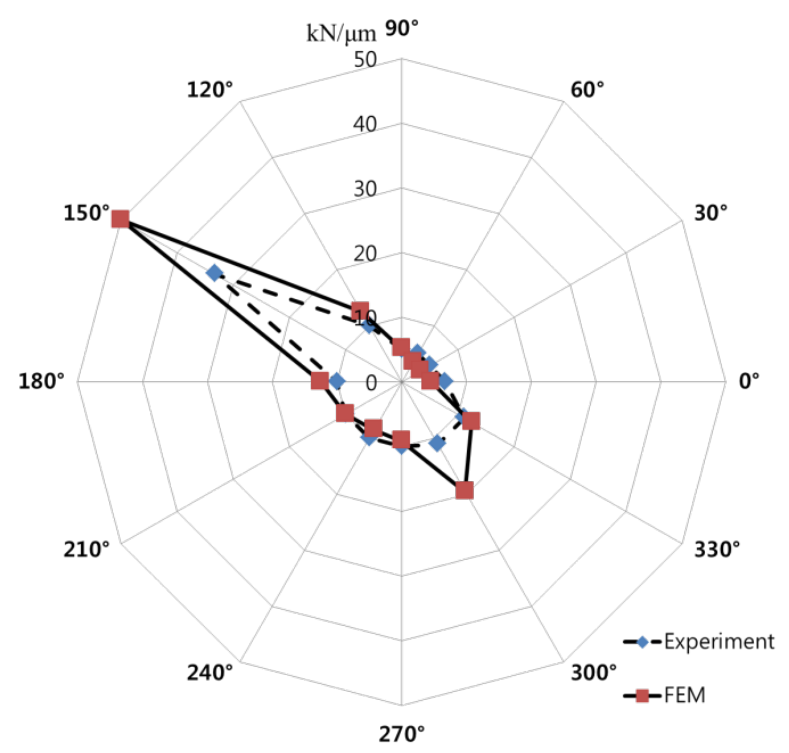

(b) In the radial direction

Figure 6. Comparison of measured and computed static stiffness of the PTD at 12 evenly indexed TCPs.

large marine engine crankshafts, has been proposed. The proposed methodology can obtain machine tool stiffness 


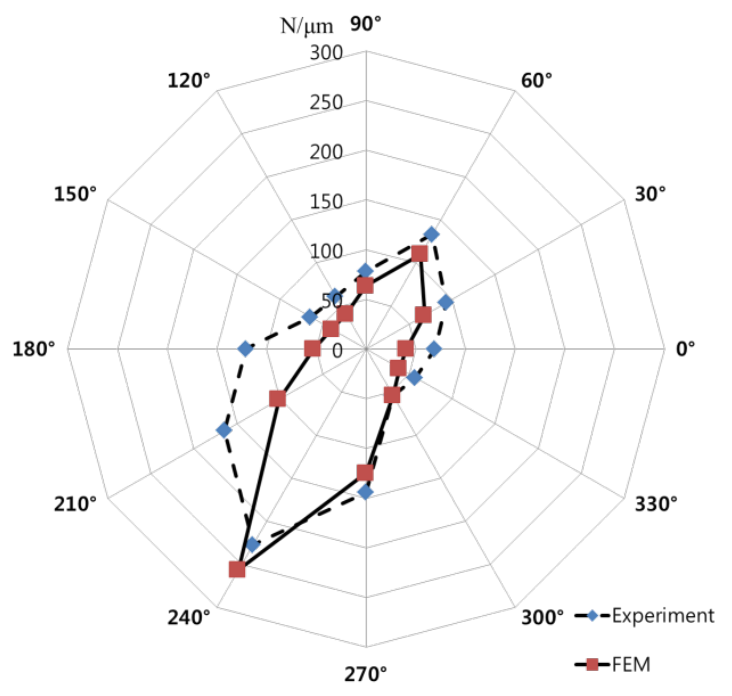

(a) In the radial direction

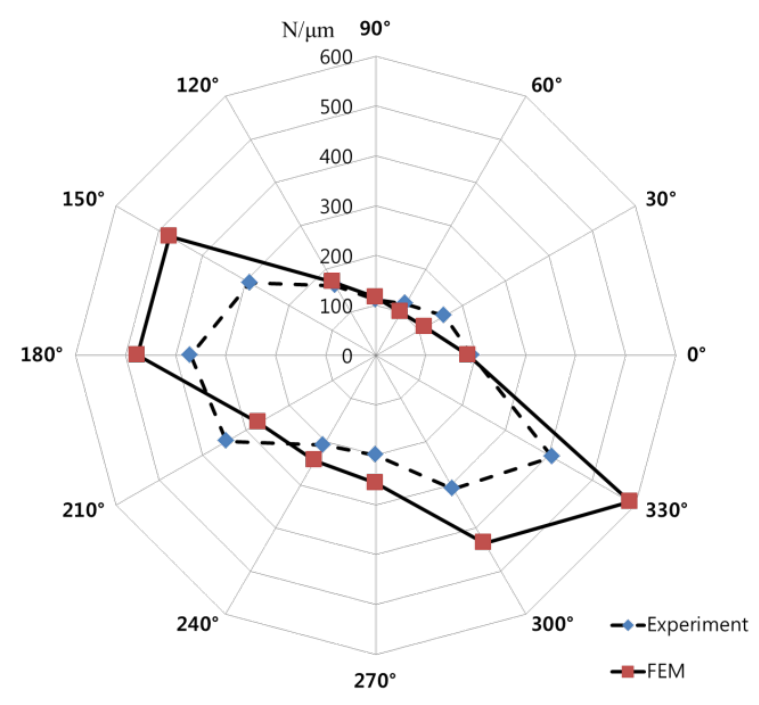

(b) In the tangential direction

Figure 7. Comparison of measured and computed dynamic stiffness of the PTD at 12 evenly indexed TCPs.

Table 2. Comparison of static stiffness of the PTD.

\begin{tabular}{ccccc}
\hline & \multicolumn{4}{c}{ Static stiffness $(\mathrm{kN} / \mu \mathrm{m})$} \\
\cline { 2 - 5 } Position $\left(^{\circ}\right)$ & \multicolumn{2}{c}{ Radial direction } & \multicolumn{2}{c}{ Tangential direction } \\
\cline { 2 - 5 } & Measured & Computed & Measured & Computed \\
\hline 0 & 2.500 & 1.522 & 6.666 & 4.545 \\
30 & 5.000 & 4.784 & 5.000 & 3.367 \\
60 & 3.333 & 3.413 & 5.000 & 3.546 \\
90 & 2.272 & 1.574 & 5.000 & 5.154 \\
120 & 1.666 & 1.370 & 10.000 & 12.500 \\
150 & 1.666 & 1.613 & 33.333 & 50.000 \\
180 & 2.500 & 2.381 & 10.000 & 12.500 \\
210 & 3.703 & 5.000 & 10.000 & 10.000 \\
240 & 4.000 & 6.666 & 10.000 & 8.547 \\
270 & 2.500 & 3.125 & 10.000 & 9.091 \\
300 & 1.666 & 1.490 & 11.111 & 19.607 \\
330 & 1.666 & 1.197 & 11.111 & 12.500 \\
\hline
\end{tabular}

Table 3. Comparison of dynamic stiffness of the PTD.

\begin{tabular}{|c|c|c|c|c|}
\hline \multirow{3}{*}{ Position $\left({ }^{\circ}\right)$} & \multicolumn{4}{|c|}{ Dynamic stiffness $(\mathrm{N} / \mu \mathrm{m})$} \\
\hline & \multicolumn{2}{|c|}{ Radial direction } & \multicolumn{2}{|c|}{ Tangential direction } \\
\hline & Measured & Computed & Measured & Computed \\
\hline 0 & 69.4 & 40.7 & 192.3 & 185.2 \\
\hline 30 & 93.5 & 68.0 & 158.7 & 113.6 \\
\hline 60 & 133.3 & 109.9 & 119.0 & 100.0 \\
\hline 90 & 78.1 & 63.7 & 111.1 & 116.3 \\
\hline 120 & 61.0 & 40.3 & 161.3 & 169.5 \\
\hline 150 & 64.1 & 39.5 & 289.9 & 476.2 \\
\hline 180 & 120.5 & 52.6 & 370.4 & 476.2 \\
\hline 210 & 163.9 & 101.0 & 344.8 & 270.3 \\
\hline 240 & 227.3 & 256.4 & 208.3 & 243.9 \\
\hline 270 & 144.2 & 125.0 & 200.0 & 256.4 \\
\hline 300 & 54.1 & 54.3 & 309.3 & 434.8 \\
\hline 330 & 57.5 & 39.1 & 408.2 & 588.2 \\
\hline
\end{tabular}

from measured compliance response by impact hammer test or random excitation test. Following the proposed method and process, PTD compliance was measured at 12 evenly indexed TCPs and then the corresponding stiffness was determined. For verifying conformance of the proposed methodology, measured stiffness has been compared with FEM analysis results. Thus the proposed methodology is proven to be appropriate for evaluating real stiffness of a PTD.

\section{Acknowledgements}

This work was supported by the Industrial Strategic Technology Development Program (Grant 10033509) sponsored by the Ministry of Trade, Industry and Energy, and HNK machine tool Co., Ltd.

\section{REFERENCES}

[1] L. Uriarte, M. Zatarain, D. Axinte, J. Yague-Fabra, S. Ihlenfeldt, J. Eguia and A. Olarra, "Machine Tools for Large Parts,” CIRP Annals-Manufacturing Technology, Vol. 62, 2013, pp. 731-750.

[2] R. Umbach, "Problems of Stiffness and Accuracy of Large Size Machine Tools,” Proceedings of 6th International MTDR, 1965, pp. 99-122.

[3] M. Weck, "Handbook of Machine Tools-Automation of Controls," Wiley, 1984.

[4] M. Weck and K. Teipel, (Translated into Korean by J. M. Lee and K. J. Kim), "Dynamic Characteristics of Machine Tool-Their Measurement and Evaluation Technology,” Dae Gwang Mun Hwa Sa Publishing Co., 1985.

[5] D. T.-Y. Huang and J.-J. Lee, "On Obtaining Machine Tool Stiffness by CAE Techniques,” International Journal of Machine Tools \& Manufacture, Vol. 41, 2001, pp. 1149-1163.

http://dx.doi.org/10.1016/S0890-6955(01)00012-8

[6] M. Arentoft and T. Wanheim, "A New Approach to Determine Press Stiffness,” CIRP Annals-Manufacturing 
Technology, Vol. 54, No. 1, 2005, pp. 265-268.

[7] M. Arsuaga, R. Lobato, A. Rodrigue and L. N. Lopez de Lacalle, "Experimental Methodology for Discretization and Characterization of the Rigidities for Large Components Manufacturing Machine,” Procedia Engineering, Vol. 63, 2013, pp. 623-631.

http://dx.doi.org/10.1016/j.proeng.2013.08.247

[8] S. H. Jang, J. H. Oh, H. S. An and Y. H. Choi, "MultiObjective Structural Optimization of a Pin Turning Device by Using Hybrid Optimization Algorithm," Proceedings of International Conference of Manufacturing
Technology Engineers, Seoul, Korea, 2012. p. 73.

[9] S. H. Jang, Y. H. Choi, S. T. Kim, H. S. An, H. B. Choi and J. S. Hong, "Development of Core Technologies of Multi-Tasking Machine Tools for Machining Highly Precision Large Parts,” Journal of the KSPE, Vol. 29, No. 2, 2012, pp. 129-138.

[10] H. S. An, Y. J. Cho, Y. H. Choi and D. W. Lee, "Development of a Multi-Tasking Machine Tool for Machining Large Scale Marine Engine Crankshafts and Its Design Technologies,” Journal of the KSPE, Vol. 29, No. 2, 2012, pp. 139-146. 